\title{
Design of Plasmalemma and Nucleolemma Specific Quantum Dots Stem Cell Labeling
}

\author{
Li $Z^{1 *}$, Xu MM ${ }^{2 *}$, Wang $L^{1 *}$, Sun $Y^{1}$, Zhou $X^{1,3}, M^{2} J^{3}$, Isaacs $W^{4}, X X^{1 \dagger}$ \\ Sciences, Xi'an 710062, P.R. China \\ ${ }^{2}$ Department of Pharmacology, Duke University Medical Center, Durham, NC 27708, USA \\ ${ }^{3}$ Ohio State University School of Medicine, Columbus, OH 43210, USA \\ ${ }^{4}$ Johns Hopkins School of Medicine, Baltimore, MD 21287, USA \\ \#Authors contributed equally
}

${ }^{1}$ National Engineering Laboratory for Resource Development of Endangered Crude Drugs in Northwest of China/CGDB, Shaanxi Normal University College of Life

\begin{abstract}
To date, there are no efficient treatments for most of human congenital, developmental, or degenerative diseases because functional cells failed to regenerate new cells following damages to original cells. Stem Cell (SC) based therapeutic approach holds tremendous promise for treating these abnormalities by replacing the damaged cells. This approach has sparked unprecedented attention in this field. However, SC researchers should adopt more robust techniques that incorporate marker genes that render stem cells visible using fluorescence and conventional microscopy. We design a unique approach to label embryonic and adult stem cells, the peptide-mediated quantum dots (QDs) SCs labeling with plasmalemma and nucleolemma specific fusion peptides. Therefore, the targeted SCs will be distinguishable by the new markers to report grafted cells from endogenous cardiomyocytes and to display the trans-differentiation from the SCs. The fluorescence strength of nanocrystal QDs will surmount the interference of the false signals originating from auto-fluorescence of cardiac tissues with their features for anti-bleaching of nonorganic dye.
\end{abstract}

Keywords: Stem cell; Quantum dot; Plasmalemma labeling; Nucleolemma labeling

\section{Introduction}

Efficient treatments are needed for most of the human congenital, developmental, or degenerative diseases as functional cells fail to regenerate new cells following damages caused by these diseases. Since Thomson et al. published the first original paper about human embryonic SCs in 1998 [1], both embryonic and adult SCs have inspired us to make use of their prospective competency to cure human disease by replacing the damaged cells. However, some recent results have raised serious disquiet [2]. The mixed results are more ambiguous in cardiovascular stem cell research. In Lancet, two papers reported that two small clinical trials were terminated due to the unexpectedly high rate of restenosis and acute/sub-acute myocardial ischemia after stem cell injection [3]. Later, two independent groups demonstrated that there was no detectable trans-differentiation after 145 transplants of haematopoetic stem cells into both normal and injured adult mice hearts. These data reports in Nature disputed the previous results published in the same journal, in which about $68 \%$ of the infarcted portion in ventricle was substituted with newly formed myocardium 9 days after ESCs injection. Furthermore, published in the September 2006 issue of $\mathrm{N}$ Eng J Med, three larger clinical trials reported contradictory results as well [4-6]. These ambivalent data require intensive attention on both basic study and clinical application by researchers performing ES therapies for human diseases. What is the major cause leading to this brutal difference? The problems with reproducibility are thought to generate from the technique of immunofluorescent microscopy [79]. It is extremely obvious, as declared in a editorial comment, "Stem cell researchers should adopt more robust techniques that incorporate marker genes that render stem cells visible using fluorescence and conventional microscopy" [8].

The SC pluripotency shows great promise in treating a wide range of human disorders, but exhibits sever difficulty needed to be overcome in cardiology application

Thomson and his colleagues published the first original paper about human embryonic stem cells in the journal Science [1]. Five ES cell lines originated from five separate embryos developed to the blastocyst stage in culture using the modified procedure for nonhuman primate ES cells [9]. The human blastocyst-derived ES cell lines have normal karyotypes, express high levels of telomerase activity and cell surface markers including stage-specific embryonic antigen (SSEA)-3, SSEA4, TRA-1-60, TRA-1-81, and alkaline phosphatase. Human ESC has pluripotent potential to derive to all three embryonic germ layers, including gut epithelium (endoderm); cartilage, bone, smooth muscle, and striated muscle (mesoderm); and neural epithelium, embryonic ganglia, and stratified squamous epithelium (ectoderm) [1]. Although Lanza thought "President's policy stopped US gaining stem-cell lead" [10], he and his colleagues still made great progress in the field of embryonic stem cell funded by private foundation, Wisconsin Alumni Research Foundation by successfully generated human ESC lines from single cells taken from pre-implanted human embryos [11]. Stem cell therapies for heart diseases are widely practiced on different animal models and a few small clinic trials on cardic dysfunction. Some of the results also increased the above disquiet. Due to limited regenerative capacity, the mammalian heart heals by scar formation after infarct. Although extensive regeneration of myocardial infarcts was reported in Nature and about $68 \%$ of the infarcted portion of the ventricle were occupied by newly formed myocardium 9 days after direct stem cell injection $[12,13]$. Field's group demonstrated that there was no detectable transdifferentiation after 145 transplants of haematopoetic stem cells into both normal and injured adult mice hearts [14]. In back-

*Corresponding author: Dr. Xuehong $\mathrm{Xu}$, National Engineering Laboratory for Resource Development of Endangered Crude Drugs in Northwest of China/CGDB Shaanxi Normal University College of Life Sciences, Xi'an 710062, P.R. China, Tel: 011-86-029-85310632; E-mail: xhx0708@snnu.edu.cn

Received August 15, 2017; Accepted September 21, 2017; Published September 25, 2017

Citation: Li Z, Xu MM, Wang L, Sun Y, Zhou X, et al. (2017) Design of Plasmalemma and Nucleolemma Specific Quantum Dots Stem Cell Labeling. J Mol Genet Med 11 289 doi:10.4172/1747-0862.1000289

Copyright: ( 2017 Wang L, et al. This is an open-access article distributed under the terms of the Creative Commons Attribution License, which permits unrestricted use, distribution, and reproduction in any medium, provided the original author and source are credited 
on-back paper in Nature, another group reported that injected stem cells (tracking by EGFP) didn't fuse with cardiomyocytes as described by other reports $[12,13,15]$, and continued to express hematopoietic cell proteins 10 days after the grafting [16]. Anversa et al. in their review on Epub ahead of print, discusses this controversy as methodological artifacts which have pervaded the field of myocardial regeneration in the last three decades. These artifacts were summarized on six categories. Three are relevant with the false fluorescence $[7,17,18]$.

The features of semiconductors nanocrystal quantum dots (QDs) can be appropriately conjugated to light up pluripotent stem cells

QDs are semiconductor crystals only several nanometers in size. Due to its specific structure and behavior, these crystals are also called the "artificial atom". QDs are actually a collection of atoms, colloidal particles consisting of a semiconductor core, with a high band gap shell and typically an outer coating layer in all three spatial directions. The atoms are arranged in a circular or elliptical manner that limits electrons and holes within a center area. The complex of electrons and valence holes are confined in "zero dimensions" behaving as a single atom. Besides the discrete quantized energy spectrum, another noteworthy property of the QDs is the small size of their semiconductor core. When a core such as cadmium selenide absorbs light, an electron is relocated from its ground state to an excited state which effectively generates a positive charge area and a negative charge at its new location. The returning of the excited state electron to its ground state releases its liberated energy in the form of light known as fluorescence (Figure 1A). This electron-hole pair can be considered as equivalent as a hydrogen atom consisting of a single proton and a single electron. The exciton Bohr radius of QD for cadmium selenide is about $5 \mathrm{~nm}$. The unique photophysical properties of QDs are dependent on the diameter of their semiconductor core. By changing the size of the core, QDs with different diameter core could tune the emission wavelength and generate fluoresce in different colors. A microemulsion template formed through self-assembly has been developed to control the size of particles precisely. A nonpolar substance (heptane), a polar substance (formamide), and a surfactant are involved in the formation of uniform dispersion of heptane droplets in formamide [19]. Using this fabrication technique, researchers are able to control the color and brightness when certain QDs are excited by ultraviolet light. Obviously, the technique makes it possible for researchers to label various target proteins simultaneously in a particular sample, which is specifically useful in clinic biopsy samples. QDs can resolve 17 fluorescence emissions, much more than polychromatic flow cytometry [20].

\section{The A1Itg and Ecad TMD peptides are designed as suitable markers to report SC plasmalemma}

In this design, the plasmalemma and nucleolemma specific TMD peptide-QD SC labeling system created by combining semiconductor nanoparticle QDs technique with transgenic targeting technique. We generate plasma membrane specific peptide and nuclear envelope membrane specific peptide targeted ESC/ASC driven by pCMV/MHC/ AHF promoter respectively.

Two plasma membrane specific peptides are the transmembrane domain (TMD) peptides from cell membrane intergral protein the alpha1 integrin (A1Itg) and E-cadherin (Ecad). Integrins and cadherins are adhesion cell membrane integral proteins that function by linking the extracellular matrix to the cytoskeleton. Working with cadherins, proteins function essentially for the apical localization of atypical protein kinase C, the Par3-LGN-Inscuteable complex and NuMAdynactin to align the spindle and differentiate proliferative basal cells outwardly. The cadherin superfamily has more than 30 members including cadherins, protocadherins, desmogleins and desmocollins.

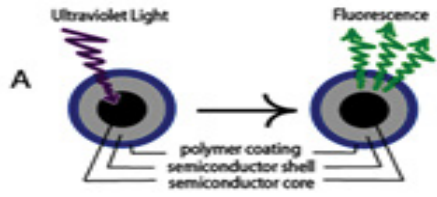

B

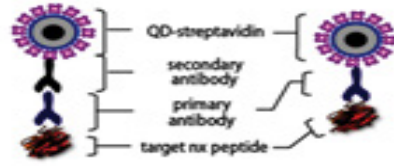

Figure 1: Schematic diagrams of $(A)$ various energy status of quantum dots between ground state and excited state; (B) targeting $Q D$ to the protein of interest in different manners.

Because the integrin alphal and E-cadherin are the best understood members in their families respectively, we chose them to perform in this study.

Alpha1 Integrin is one of 18 alpha subunits which consist of one chain of integrin heterodimers. The combination of the alpha subunits and eight subunits generates 24 unique integrins. Most of the integrins have long extracellular domains which bind to ECM ligands such as fibronectin and laminin, and short cytoplasmic domains of about 60 amino acids, which link their receptors to the cytoskeleton. The extracellular domain of alphal integrin contains seven homologous repeats of about 30 to 40 amino acids with 20-30 amino-acid stretch in between followed and three cation-binding sequences [21,22]. The TMD with 25-amino acid sequence will be used as the peptide to target stem cells and the 28 amino-acid signal peptide will be utilized to direct the peptide to the plasma membrane.

E-cadherin consists of five cadherin modules in its extracellular domain and an intracellular domain. A 21 amino-acid signal-peptide locates at the amino terminal and a 28 aminoacid transmembrane domain situates between the extracellular and the intracellular domain $[23,24]$. The signal sequence and the peptide of the TMD of E-cadherin will be employed to carry on this study (Figure $2 \mathrm{~A}$ ).

\section{The LBR and NUANCE TMD peptides are designed as suitable markers to report SC Nucleolemma}

Two nuclear envolope membrane specific peptides are the transmembrane domain peptides from nuclear membrane protein the Lamin B receptor (LBR) and NUANCE (NUcleus and ActiN Connecting Element). LBR TMD is the peptide that we design to target the inner nuclear membrane and NUANCE TMD is the peptide that we plan to target the outer nuclear membrane in ESC/ASC.

The nuclear envelope has three major components i.e., nuclear lamina, nuclear pore complexes, and nuclear membranes Lamin B receptor (LBR) is an integral protein of the inner nuclear membrane and named for its interaction with one of the nuclear lamina proteins, lamin $B$ additional to chromatin DNA. Human LBR, which is well investigated by different groups $[25,26]$, comprises two globular domains (I and II), which are separated by a hinge domain that is involved in DNA binding and has two sequences (NLS 1 and NLS 2) which fit the sequence of the nucleoplasmin-like bipartite motif that was demonstrated as nuclear localization signals (NLS). A 25-amino acid spacer is located between the NLS 1 and NLS 2 [27]. The loops between eight transmembrane domains and carboxyl terminus sited after the globular II domain form three nucleoplasmic domains. We design to engineer the complex peptide into ESC/ASC. The complex peptide consists of NLS 1 and NLS 2 with the spacer, TMD 1 or TMD 1 and TMD 2 plus loop 1 .

Beside the fusion peptide targeting to inner nuclear membrane, we also design to target outer nuclear membrane with a peptide from the TMD of NUANCE. NUACE was identified as a novel protein with an 
A. Plasmalemma Targeting Fusion Peptides

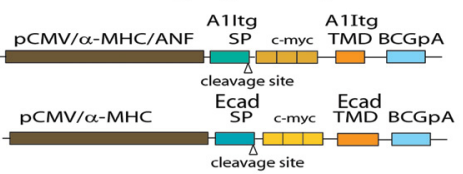

B. Nucleolemma Targeting Fusion Peptides

LBR
PCMV/ $\alpha-M H C$
pCMV/ $\alpha-M H C / A N F \quad c-m y c$
NLS 3,4

Figure 2: The targeting DNA constructs of plasmalemma specific fusion peptides (A) and nucleolemma specific fusion peptides (B) driven by pCMVMHC/ANF (not to scale).

alpha-actinin-like actin-binding domain followed by 22 dystrophinlike spectrin repeats [28]. A C-terminal transmembrane domain, which is responsible for the targeting the nuclear envelope, is included in the Klarsicht-like domain (KSL). The TMD of NUNACE is situated in KSL domain. The NUANCE is a giant protein of 6,885 amino acids with four nuclear localization signals and functions functioning as connectors linking the nuclear and the microfilament system by binding to actin. In this project, we also design to target the fusion peptide consisting of KLS peptide (TMD included) with the NLS-3 and NLS-4 into the outer nuclear membrane of ASC/ESC (Figure 2B).

The nucleolemma and plasmalemma specific constructs designed above were targeted with standard approach of electroporation. The positive colonies with stemness under neomycin selection were maintained as the labeled stem cells [29] and then used to further applications on regeneration medicine.

\section{Conclusion and Future Prospects}

One of the cutting-edge applications of QDs in biomedical analysis is that it's used as artificial fluorophore instead of various kinds of traditional organic dyes. Compared with the traditional dye, QD is remarkably resistant to photobleaching [22], because it emits light at a distinctive wavelength that is independent of the excitation source. It is known that photobleaching always complicates the observation and measurement of fluorescent molecules because the molecules will eventually be destructed by the light exposure necessary to stimulate them into fluorescing. Providentially, in our design, QDs solve this obstacle for the application especially in cardiac regeneration medicine although the design has limitation on regeneration study of non-cardiac tissues which could be rescued when other tissue-specific promoter applied. Our result can be employed to monitor interactions within and among cell growth and differentiation with strong potential to unveil the fundamental mysterious of SC regeneration with in cardiology.

\section{Competing Interests}

The submitted work was currently applying for patents relating to the content of the manuscript. The authors declare no other competing interests.

\section{Funding and Acknowledgements}

This work was supported by the NSFC (\#31371256/31571273/31771277), the Foreign Distinguished Scientist Program (\#MS2014SXSF038), the National Department of Education Central Universities Research Fund (\#GK20130100/201701005/GERP-17-45), and US Maryland Stem Cell Research Fund (2009MS-CRFE008300).

\section{References}

1. Thomson JA, Itskovitz-Eldor J, Shapiro SS, Waknitz MA, Swiergiel JJ, et al. (1998) Embryonic stem cell lines derived from human blastocysts. Science 282: $1145-1147$.

2. Steele AN, MacArthur JW, Woo YJ (2017) Stem cell therapy: Healing or hype? Why stem cell delivery doesn't work. Circ Res 120: 1868-1870.
3. Behfar TA (2016) Stem cell therapy for heart failure: Ensuring regenerative proficiency. Trends Cardiovasc Med 26: 395-404.

4. Vulliet PR, Greeley M, Halloran SM, MacDonald KA, Kittleson P (2004) Intracoronary arterial injection of mesenchymal stromal cells and microinfarction in dogs. Lancet 363: 783-784.

5. Bergmann O, Bhardwaj RD, Bernard S, Zdunek S, Barnabé-Heider F, et al (2009) Evidence for cardiomyocyte renewal in humans. Science 324: 98-102.

6. Schachinger V, Erbs S, Elsasser A, Haberbosch W, Hambrecht R, et al. (2006) Intracoronary bone marrow-derived progenitor cells in acute myocardia infarction. N Eng J Med 355: 1210-1221.

7. Assmus B, Honold J, Schächinger V, Britten MB, Fischer-Rasokat U, et al (2006) Transcoronary transplantation of progenitor cells after myocardial infarction. N Eng J Med 355: 1222-1232.

8. Anversa P, Leri A, Rota M, Bearzi C, Bearzi C, et al. (2007) Concise review: stem cells, myocardial regeneration, and methodological artifacts. Stem Cells 25: 589-601.

9. Nature Editorials (2004) No consensus on stem cells. Nature 428: 587.

10. Chien KR (2004) Stem cells: Lost in translation. Nature 428: 607-608.

11. Lanza R, Green RM (2005) Bush's policy stopped US gaining stem-cell lead. Nature 438: 422.

12. Klimanskaya I, Chung Y, Becker S, Lu SJ, Lanza R, et al. (2006) Human embryonic stem cell lines derived from single blastomeres. Nature 444: 481-485.

13. Orlic D, Kajstura J, Chimenti S, Jakoniuk I, Anderson SM, et al. (2001) Bone marrow cells regenerate infarcted myocardium. Nature 410: 701-705.

14. Alvarez-Dolado M, Pardal R, Garcia-Verdugo JM, Fike JR, Lee HO, et al. (2003) Fusion of bone-marrow-derived cells with Purkinje neurons, cardiomyocytes and hepatocytes. Nature 425: 968-973.

15. Murry CE, Soonpaa MH, Reinecke H, Nakajima H, Nakajima HO, et al. (2004) Haematopoietic stem cells do not transdifferentiate into cardiac myocytes in myocardial infarcts. Nature 428: 664-668.

16. Balsam LB, Wagers AJ, Christensen JL, Kofidis T, Weissman IL, et al. (2004) Haematopoietic stem cells adopt mature haematopoietic fates in ischaemic myocardium. Nature 428: 668-673.

17. http://www.sciencemag.org/news/2017/04/10-million-settlement-over-allegedmisconduct-boston-heart-stem-cell-lab

18. https://forbetterscience.com/2015/11/21/is-piero-anversa-heading-tocardiocentro-ticino-in-switzerland/

19. Zhang H, Jin M, Xiong $Y$, Lim B, Xia Y (2013) Shape-controlled synthesis of Pd nanocrystals and their catalytic applications. Acc Chem Res 46: 1783-1794.

20. Chattopadhyay PK, Price DA, Harper TF, Betts MR (2006) Quantum dot semiconductor nanocrystals for immunophenotyping by polychromatic flow cytometry. Nature Medicine 12: 972-977.

21. Park YK, Goda Y (2016) Integrins in synapse regulation. Nat Rev Neurosci 17 745-756.

22. Xia S, Kanchanawong $P$ (2017) Nanoscale mechanobiology of cell adhesions. Semin Cell Dev Biol S1084-9521: 30191-X.

23. Balda MS, Matter K (2016) Tight junctions as regulators of tissue remodelling. Curr Opin Cell Biol 42: 94-101.

24. Priest AV, Shafraz O, Sivasankar S (2017) Biophysical basis of cadherin mediated cell-cell adhesion. Exp Cell Res 358: 10-13.

25. Guénantin AC, Briand N, Bidault G, Afonso P, Béréziat V, et al. (2014) Nuclear envelope-related lipodystrophies. Semin Cell Dev Biol 29: 148-157.

26. Olins AL, Rhodes G, Welch DB, Zwerger M, Olins DE, et al. (2010) Lamin B receptor: Multi-tasking at the nuclear envelope. Nucleus 1: 53-70.

27. Robbins J, Dilworth SM, Laskey RA, Dingwall C (1991) Two interdependent basic domains in nucleoplasmin nuclear targetin 8 sequence: Identification of a class of bipartite nuclear targeting sequence. Cell 64: 615-623.

28. Phatak R, Gupta SK, Maheshwari P, Das A, Sali SK, et al. (2017) Crysta structure of Crystal structure of $\mathrm{Ba}_{2}\left(\mathrm{La}_{0727} \mathrm{Ba}_{0.182} \mathrm{M}_{0.091}\right) \mathrm{MO}_{6}(\mathrm{M}=\mathrm{Nb}, \mathrm{Sb}$ $\mathrm{Bi})$ : symmetry nuance identified in photoluminescence and IR spectroscopy studies. Dalton Trans 46: 1694-1703.

29. Xu MM, Jones OD, Wang L, Zhou X, Davis HG, et al. (2017) Characterization of tubular liquid crystal structure in embryonic stem cell derived embryoid bodies. Cell Biosci 7: 3-6. 